\title{
Intrapersonal Emotional Responses to the Inquiry and Advocacy Modes of Interaction: A Psychophysiological Study
}

\author{
Ilkka Leppänen ${ }^{1}$ (D) Raimo P. Hämäläinen ${ }^{2}$ - Esa Saarinen ${ }^{3}$. \\ Mikko Viinikainen ${ }^{2}$
}

Published online: 6 July 2018

(c) The Author(s) 2018

\begin{abstract}
In negotiations and group decision making we can use two characteristically different interaction modes: inquiry and advocacy. Inquiry refers to an interested and explorative interaction mode, and advocacy to an assertive and narrow mode. Although these modes have been studied in organizational behavior literature, the intrapersonal emotional responses to the inquiry and advocacy modes remain yet unexplored. We explored intrapersonal emotions by facial electromyography and skin conductance responses and by emotional empathy self-reports. The subjects were prompted to adopt the two modes in hypothetical encounters with another person. We found that Duchenne smiles were specific to the inquiry mode, that emotional arousal showed specificity to the expressions, and that emotional empathy predicts expressiveness in the inquiry treatment. We discuss the implications of these results to the use of the interaction modes and the related possibilities of influencing group interaction by influencing one's own internal emotional state in group decisions.
\end{abstract}

Keywords Inquiry · Advocacy · Intrapersonal emotions · Group interaction · Psychophysiological responses

Electronic supplementary material The online version of this article (https://doi.org/10.1007/s10726-01 8-9584-8) contains supplementary material, which is available to authorized users.

Ilkka Leppänen

i.leppanen@lboro.ac.uk

1 School of Business and Economics, Loughborough University, Loughborough LE11 3TU, UK

2 Systems Analysis Laboratory, Aalto University, P.O. Box 11100, 00076 Aalto, Finland

3 Department of Industrial Engineering and Management, Aalto University, P.O.

Box 15500, 00076 Aalto, Finland 


\section{Introduction}

Different ways of interacting affect behavior in negotiations. Some ways of interacting may have intended effects that are beneficial for the negotiation, such as generating more insights or trust or persuading group members of certain courses of action, but also unintended effects, such as creating friction, distrust, and disagreement. Much literature has focused on the interpersonal effects of dyadic or group interaction in negotiations and has related these effects on how successful the interaction is in terms of the achieved outcomes. However, equally important is to understand intrapersonal effects - how one's emotional reactions to different ways of interacting affects within oneself (see e.g. Morris and Keltner 2000, for a definition of intrapersonal effects of emotions). Different ways of interacting can give rise to different emotional responses in oneself, which can then be reflected in the person's own facial emotional expressions and in other ways that emotions are manifested. This will again influence the collective emotional landscape in the dyad or group in which one is interacting (Kappas 2013).

Both intrapersonal and interpersonal emotions have been extensively studied in negotiation and group settings; see e.g. van Kleef et al. (2004, 2017). To name a few examples, it is well known that moods are contagious in groups making managerial decisions (Barsade 2002), and that language and emotions play a role in online negotiations and negotiation support systems where there is no direct facial contact (see e.g. Brett et al. 2007; Hine et al. 2009; Broekens et al. 2010; Griessmair et al. 2015). Some evidence of how emotions affect negotiators in an isolated environment may be drawn from studies using online interactions in group decision making and negotiations where communication is possible only via computers. However, the review by Derks et al. (2008) concludes that emotions in online communication play a very similar role as emotions in offline communication.

We study the question whether emotions that naturally arise in certain types of interactions have intrapersonal effects even if the communication does not have an emotional component. By these types of interactions we mean communication modes in which emotions are not mediated nor prompted. Adopting a certain behavioral interaction style or mode in a negotiation or in the group that is making decisions generates emotional effects in the group, which in turn may be advantageous or disadvantageous for attaining a desired outcome. Before these emotional effects become interpersonal, however, they are experienced within oneself and may be manifested as emotional expressions or autonomic responses. With this perspective in mind we set to explore whether different ways of interacting have different intrapersonal emotional effects on oneself, which consequently has an impact on the other participants.

We choose from the literature two interaction modes that are developed for structured interaction, inquiry and advocacy, and arrange a laboratory experiment to study their intrapersonal emotional correlates. These interaction modes, designed to introduce constructive conflict in a group (Schweiger et al. 1986), have been studied a lot in the literature but the mechanisms that they trigger are not well understood. A person with an inquiry mode shows interest in the others' points of views and asks questions and explores different possibilities. A person with an advocacy mode approaches the others with a narrow and assertive way and emphasizes her own points of view. Inquiry is suggested to be related to improved organizational learning (Argyris and 
Schön 1978) and to the lowering of inhibitory defensive routines (Schein 2013). Such phenomena are naturally desirable also in group decision and negotiation settings. Evidence from laboratory experiments shows that introducing and balancing inquiry and advocacy in the decision making process improves decisions over a simple process where only expert recommendations are followed and no conflict between the decision makers is present (Schwenk 1990). Inquiry is also an essential component in dialogue (see e.g. Slotte and Hämäläinen 2015). The organizational learning literature also emphasizes the need for the systems perspective in understanding and improving organizational behavior. ${ }^{1}$

In our experiment, the subjects were prompted to adopt an inquiry mode, an advocacy mode, and a passive (neutral) viewing mode in simulated encounters with other persons who were represented by facial pictures accompanied by textual statements. We then measured emotions in the alternative modes in a within-subject design. To distinguish genuine positive emotional expressions from non-genuine ones, we measured both the Duchenne and the non-Duchenne smiles. ${ }^{2}$ The Duchenne smile is often associated with positively valenced stimuli and it is formed by contracting both the zygomaticus major and the orbicularis oculi muscles in the face, whereas the non-Duchenne smile involves only the zygomaticus major (Ekman et al. 1990; Frank and Ekman 1993). The negative emotional expressions were represented by furrowed eyebrows where the corrugator supercilii muscle is contracted. The furrowed brows expression is often associated with negatively valenced stimuli (Larsen et al. 2003). These facial expressions were measured by facial electromyography (EMG). To represent internal emotional states, we measured activation of the sympathetic part of the ANS, or emotional arousal, by the skin conductance response (SCR). To include somatic responsivity as a control variable in the analysis we formed an empathy score for each subject using a 33-item self-report questionnaire.

Earlier studies on inquiry and advocacy have studied their effect on others and the group (see Schwenk 1990). We contribute to this literature by describing the intrapersonal emotional effects of inquiry and advocacy. Our contribution will thus offer an increased understanding of the whole picture of the interaction in negotiations and group decisions. Looked from another perspective, we demonstrate that there is a possibility that one can alter one's influence on the group's behavior by influencing oneself through intrapersonal emotions.

\footnotetext{
1 The concept of systems intelligence was introduced as an extension to this literature by Hämäläinen and Saarinen (2004), see also Luoma et al. (2008, 2011). Systems intelligence presents a theory of how we can successfully interact with people in systemic settings such as in groups and in this theory communication in the inquiry mode is seen as an essential tool. The construct of systems intelligence has eight factors some of which relate directly to how people are encountered and are thus directly related to group interaction (Törmänen et al. 2016).

2 It is important to be able to differentiate genuine from non-genuine positive emotional expressions. This is because it is possible that a nongenuine positive emotional expression is displayed in the advocacy mode, for example, by a negotiator who wants to give a false emotional signal. Yet it is possible that the other person in fact sees that this is not a genuine signal.
} 


\section{Theoretical Background}

Much of the literature on emotions emphasizes the regulatory nature that emotions play in human interaction. Interpersonal emotions regulate social interaction, and intrapersonal emotions regulate individuals, and all these effects form complex interrelated layers, leading to blending of the concepts of emotion generation and regulation (Kappas 2013). For comprehensive reviews on emotions in negotiations, see e.g. Druckman and Olekalns (2008) and Martinovski (2015a).

In face-to-face negotiations behaviors such as nonverbal signs and speech intonation are often used to express emotion (Martinovski 2015b). Via these behavioral tendencies emotions have interpersonal effects, i.e. emotions affect and are transferred onto others in interaction (Christov-Moore and Iacoboni 2015; Olekalns and Druckman 2015; Griessmair 2017). Specific interpersonal effects of emotions in negotiations include emotional contagion (e.g. Thompson et al. 1999) and conveying behavioral intentions (Fridlund 1994). Through face-to-face interactions, shared or collective emotions may then arise (Von Scheve and Ismer 2013) that may influence how well a whole strategic change in an organization can be managed (see e.g. Sanchez-Burks and Huy 2009).

Various intrapersonal effects of emotions in social interaction are known to exist. For example, the disgust emotion produces avoidance towards moral transgressors (Chapman and Anderson 2013). It has been hypothesized that the anger emotion has evolved to orchestrate behavior in a person that creates incentives in the target of anger to produce concessions (Sell et al. 2009). People also know how to use anger strategically in competitive interactions (Gneezy and Imas 2014). Anger causes more concessions (Sinaceur and Tiedens 2006; Van Kleef et al. 2004) as well as an anger response in the opponent (Friedman et al. 2004), but experienced anger may be counterproductive (Allred et al. 1997). In negotiation and decision making, it is known that humans resort to intrapersonal emotion regulation strategies such as cognitive reappraisals, and these strategies have been shown to reduce decision biases that are believed to be emotional in origin, such as risk aversion (Heilman et al. 2010). Indeed, emotion regulation may have instrumental value in negotiations (Tamir and Ford 2012).

Deception and dishonesty have received interest in the negotiation literature (see e.g. Olekalns and Smith 2007) and it has been argued that groups make people more dishonest (Sutter 2009; Kocher et al. 2017). The link between deception and emotions can be traced to violations of norm perceptions (Schweitzer and Gibson 2008).

Positive emotion expressions are known to have various interpersonal and outcomerelated effects, such as increasing cooperativeness and reducing conflict and leading to better negotiation outcomes than negative emotions (Barsade 2002; Kopelman et al. 2006; Hine et al. 2009). Positive emotions are also known to carry informational value in decisions despite being seemingly irrelevant (Steffen et al. 2009). However, there is less research on the intrapersonal effects of positive emotions on behavior. Positive emotions are known to broaden attention and increase cognitive flexibility (Fredrickson 2001) and promote in-group identity (Johnson and Fredrickson 2005). However, positive and negative emotions affect differently on cognition. Positive emotions lead to different information processing strategies than negative emotions (Forgas and George 2001). Whereas positive emotions broaden attention, negative emotions narrow attention and bias it against threats (Frijda 1994). Thus, the literature on how 
emotions affect cognition supports, indirectly, our argument that emotions have intrapersonal effects in group interactions.

Our goal in this article is to contribute into the literature how positive and negative intrapersonal emotions arise in different ways of interacting in groups. This will help the understanding of the functions of these emotions in group interaction. We are interested in the emotional effects of the two interaction modes of inquiry and advocacy and conduct an explorative experimental study. Our main assumption regarding the experimental results is that the valence (i.e. positivity-negativity) of the intrapersonal emotions elicited by the different interaction modes can be traced to the positive-negative domain from facial emotional expressions when each interaction mode is displayed. If this assumption is correct, then we should observe that one interaction mode is "positive" and the other is "negative". The changes in valence are observed in comparisons of the emotional expressions in the interaction mode to the emotional expressions in the passive mode. We are also interested in finding out whether the "positive" mode, if it can be observed, is related to genuine positive emotional expressions. In this analysis the comparisons are made within the respective interaction modes and between the emotional expressions. This analysis is conducted because it is important to be able to differentiate genuine from non-genuine positive emotional expressions. It is possible that a nongenuine positive emotional expression is displayed in an interaction mode by, for example, a negotiator who wants to display false emotional signals.

To find evidence for the argument that intrapersonal emotions are represented as internal emotional states and not just as facial expressions that support the communication of emotions and thus their interpersonal effects, we explore the autonomous nervous system correlates of each interaction mode. However, as emotional arousal does not directly reflect the valence of emotions but only emotional intensity (Larsen et al. 2008), investigation of emotional arousal is not rooted to positivity or negativity of emotions. In this investigation our interest is to learn whether the two interaction modes elicit different levels of emotional arousal, and how arousal correlates with the different emotional expressions within the modes.

Finally, we study individual-level variability in the expression of intrapersonal emotions using an empathy questionnaire. Empathy is known to affect how responsive individuals are to emotions (Mehrabian and Epstein 1972). We assume that subjects who have a higher empathy score are more expressive than subjects who have a lower empathy score, and that this is also reflected in the treatment effects.

\section{Experiment}

\subsection{Procedure}

During the experiment, the subjects sat still in a dimly lit room and underwent three treatments: Inquiry, advocacy, and passive. The stimuli were the same in each treatment and consisted of a set of 26 facial photographs with written statements below the photograph. The statements represented the opinion of the person in the photograph on a topic which varied from person to person. Examples of statements included: 'I 
am terrified of gene manipulated food' and 'Shopping makes me happy'. The subjects were instructed to silently take either an inquiry approach (inquiry treatment) or an advocacy approach (advocacy treatment) to the stimuli, or to observe the stimuli passively (passive treatment). The photographs, statements, and the experimental instructions are available in the Supplemental Material.

Each photograph was shown for $18 \mathrm{~s}$ with 5-s breaks. The same set of photographs was shown in each treatment in randomized order. The order of the inquiry and advocacy treatments was randomized between the subjects. To allow the main treatment effects to be compared with the passive treatment, the passive treatment was always presented after the main treatments. A 5-min baseline was measured at the beginning.

\subsection{Measurements}

The EMG and SCR data were obtained using bipolar $\mathrm{Ag} / \mathrm{AgCl}$ electrodes. The measurements were conducted with Nexus-4 equipment and recorded with BioTrace+ software (MindMedia B.V., The Netherlands). The EMG data was obtained from the corrugator supercilii, zygomaticus major, and orbicularis oculi facial muscle sites at the left hemisphere of the face. The placements of the EMG electrodes followed the recommendations of Fridlund and Cacioppo (1986). The SCR data was obtained from the non-dominant hand index and middle fingers.

The 2048-Hz EMG data was band pass filtered between 90 and $200 \mathrm{~Hz}$, smoothed, rectified and logarithmized. The EMG scores were obtained with a similar procedure as used by Johnson et al. (2010). This procedure was conducted to ensure that the emotional expressions were mutually exclusive. The signal during each 18-s stimuli was averaged into 3 -s bins, the mean from the 60-s baseline signal was subtracted from each bin, and each bin was coded active for a positive remainder. Therefore, the baseline signal was considered as the muscle activation threshold during each stimuli. Then, the facial expressions were coded as follows. A Duchenne smile was registered if both the zygomaticus major and the orbicularis oculi were active but the corrugator supercilii inactive. A non-Duchenne smile was registered if only the zygomaticus major was active. In this way, the Duchenne and non-Duchenne smiles are mutually exclusive. A furrowed brow was registered if only the corrugator supercilii was active. Each EMG score therefore has a count value 0-6, and this is referred to as EMG bin count of the respective muscle area. The $128-\mathrm{Hz} \mathrm{SCR}$ data was deconvoluted into an integrated SCR (ISCR) score (Benedek and Kaernbach 2010) and logarithmized. The ISCR score has unit $\mu$ Ss.

Before the measurement began the subjects filled a 33-item questionnaire measuring empathy (Mehrabian and Epstein 1972, p. 528). An empathy score 0-100 was calculated from the responses.

\subsection{Participants}

A total of 40 healthy subjects participated. After the experiment, the subjects reported in writing what they had thought during the inquiry and advocacy treatments. The reports were used to decide which subjects did not understand the task and should 
be excluded from further analysis. We defined understanding the task as reporting different thoughts in the inquiry and advocacy modes that roughly corresponded to the task instruction. To ensure objectivity in the decision to exclude subjects, we used a panel of three outside observers. The observers, who were research assistants and did not know the goals of the experiment, were asked to read the reports and evaluate subjects' understanding of the task. The panel then discussed which subjects should be excluded and came to an unanimous decision. As a result, seven subjects were excluded. The remaining number of subjects was 33 ( $M_{\text {age }}=34.6$ years, age range: 22-61 years, 17 women).

All subjects gave their written consent on participating in the experiment. The experiment was approved by the ethics committee of Aalto University and conducted in accordance with the Declaration of Helsinki.

\section{Results}

The results were analyzed using linear mixed models (LMMs) where the subjects were treated as random effects. This takes the between-subject heterogeneity in the psychophysiological measurements into account. The degrees of freedom were calculated by Satterthwaite approximations. We report the $S D$ of random effects as $\sigma_{0}$ (residual) and $\sigma_{1}$ (slope). To account for the possibility of habituation, time (indicating the stimulus number) is included as an independent variable in the main analyses. For six subjects, the SCR signal failed to appear at all or failed to appear at some point during the experiment. These subjects are treated as missing values in the analyses on emotional arousal.

Figure 1 shows the main results. We see that the Duchenne smiles are exclusively related to the inquiry treatment. In that treatment the number of Duchenne smiles is significantly higher than in the passive treatment, while in the advocacy treatment the number of Duchenne smiles is not significantly different from the Duchenne smile numbers in the passive treatment. We also find that there were more both Duchenne and non-Duchenne smiles in the inquiry treatment than in the passive treatment. Thus, the inquiry treatment generated both genuine and non-genuine positive emotional expressions. In the advocacy treatment the number of non-Duchenne smiles was higher than in the passive treatment. Thus, the genuine positive emotional expressions were above the passive treatment numbers only in the inquiry treatment, whereas the nongenuine positive emotional expressions were above the passive treatment numbers in both the inquiry and the advocacy treatments. These results imply that only the inquiry mode generates genuine positive emotional expressions whereas the advocacy mode generates also nongenuine positive emotional expressions.

We do not find a higher number of furrowed brows in the advocacy treatment than in the passive treatment. However, there are a lower number of furrowed brows in the inquiry treatment than in the passive treatment (Fig. 1). In other words, the furrowed brows expression is inhibited in the inquiry treatment. This suggests that there is an inverse relationship between furrowed brows and the Duchenne smiles that is specific to the inquiry treatment but not observed in the advocacy treatment. We can also explore this inverse relationship a bit more, namely the relationship between the bin 


\section{Duchenne}

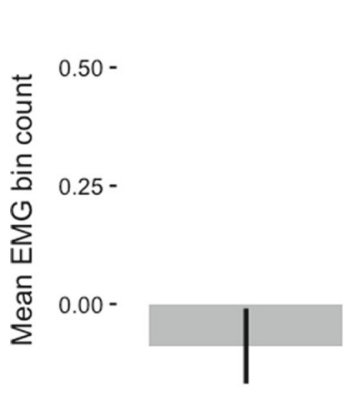

$-0.25-$

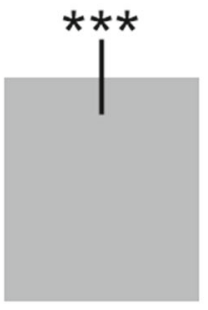

Advócacy nquiry
Furrowed brows

$0.4-$

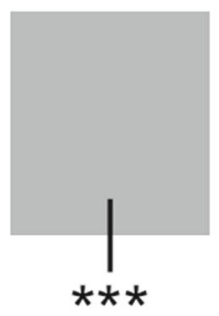

Advo'cacy

Inquiry
non-Duchenne

$0.3-$

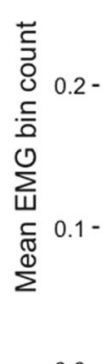

$0.0-$

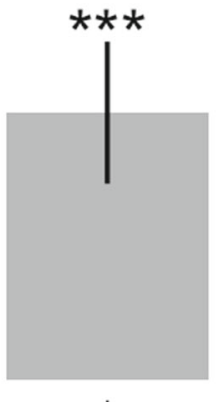

Advócacy

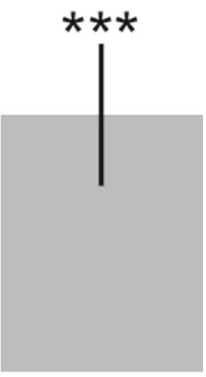

Inquiry

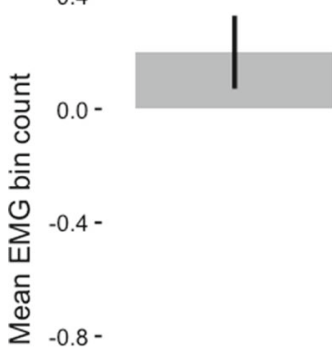

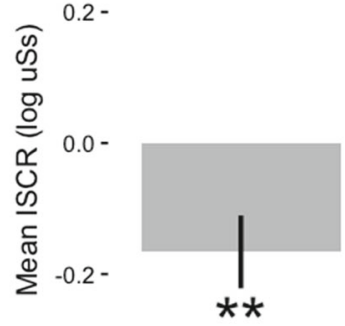

Advocacy

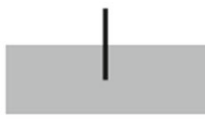

Arousal

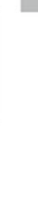

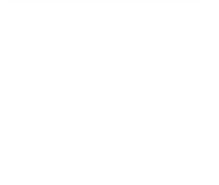

Inquiry

Fig. 1 LMM estimates of mean bin counts of EMG for the three facial expressions and ISCR for arousal. Note: The number of observations is 2496 in models with EMG bin counts and 2106 in the model with ISCR. The reference treatment, passive, is moved to zero, i.e. the bar heights represent deviations from the passive treatment level. The mean levels of EMG bin counts in the passive treatment are $0.26(S D=0.95)$ for Duchenne smiles, $0.13(S D=0.68)$ for non-Duchennes, and $2.17(S D=2.47)$ for furrowed brows. The mean ISCR score in the passive treatment is $0.46(\mathrm{SD}=0.51) \mu \mathrm{Ss}$. Time is included as an independent variable. The error bars represent standard errors of the coefficients estimated by the LMMs. The random effect standard deviations are: $\sigma_{0}=1.0, \sigma_{1}=0.62$ (Duchenne), $\sigma_{0}=0.65, \sigma_{1}=0.62$ (non-Duchenne), $\sigma_{0}$ $=1.7, \sigma_{1}=1.6$ (Furrowed brows), $\sigma_{0}=0.66, \sigma_{1}=0.40$ (Arousal). Asterisks represent significance levels: $* * p<0.01, * * * p<0.001$. Significance is calculated with respect to the zero level (passive treatment)

counts of the furrowed brows expressions and the Duchenne and non-Duchenne smiles. This reveals that the furrowed brows bin count at each stimulus is indeed inversely related to the bin counts of the two smiles (LMM, Duchenne coefficient $-0.27, t=$ $-8.2,2488.6 d f, p<0.001$, non-Duchenne coefficient $-0.31, t=-5.9,2495.1 d f, p$ $<0.001, \sigma_{0}=1.7$ and $\sigma_{1}=1.5$ ).

Based on observations shown in Fig. 1, our main assumption about the valence of the modes is partially supported, in the sense that the inquiry mode is "positive" because it elicits the positive emotional expressions but not the negative one. The 
advocacy mode only elicits the non-genuine Duchenne smiles and therefore has an inconclusive relationship to the facial expressions, i.e. we cannot confirm whether it is "positive" or "negative" in nature.

There are in total 646 Duchenne smiles in the inquiry treatment, versus 174 nonDuchenne smiles in that treatment. An LMM comparing the difference in the smiles within the inquiry treatment confirms that there are significantly more Duchennes than non-Duchennes at the subject level (dependent variable bin count, independent variable EMG dummy that has value 0 for Duchenne and 1 for non-Duchenne, coefficient $-0.56, t=-10.73,1632 d f, p<0.001, \sigma_{0}=1.08$ and $\left.\sigma_{1}=0.80\right)$. In the advocacy treatment, the total number of Duchenne smiles is 178 , and the total number of nonDuchenne smiles is 180 , and this difference is not significant in a similar LMM as above (dependent variable bin count, independent variable EMG dummy that has value 0 for Duchenne and 1 for non-Duchenne, coefficient $0.0024, t=0.063,1632 d f, p=$ $0.95, \sigma_{0}=0.78$ and $\sigma_{1}=0.52$ ). Thus, the number of genuine smiles is clearly highest in the inquiry treatment compared to the advocacy treatment and compared to the non-genuine smiles.

We find that the negative emotional expression, the furrowed brows, is inhibited in the inquiry mode with respect to passive viewing. Although this inhibition may seem surprising, previous research concerning the neurophysiology of the corrugator supercilii has reported that its activation can be reciprocal to negative and positive valence and antagonistic to the zygomaticus major (Dimberg and Lundquist 1990) or otherwise restricted in specific positive emotion stimuli (Heckmann et al. 2003). The inhibition of furrowed brows and activation of the Duchenne and the non-Duchenne smiles during the same stimuli implies that the inquiry mode did not only include the use of the smiles but also expressions where control of the brow musculature played a role. Particularly notable is that the corrugator supercilii activity was significantly lower in the inquiry treatment than in the passive treatment, which may indicate that subjects volitionally inhibit the furrowed brows expression when instructed to adopt the inquiry interaction mode (see also Kappas et al. 2000).

Figure 1 shows that there is less emotional arousal in the advocacy treatment than in the passive treatment, and that the level of arousal in the inquiry treatment is not different from its level in the passive treatment. However, if we run the LMM again without the inquiry treatment, we do not find a significant difference in arousal level between the advocacy and passive treatments (coefficient 0.012, $t=0.28,1392 \mathrm{df}$, $p=0.78, \sigma_{0}=0.37, \sigma_{1}=0.36$ ). Therefore, the relationship between arousal and the interaction modes remains unconfirmed.

To see the relationships between arousal and the expressions, we next study how the expressions explain the arousal level in each treatment. Table 1 shows results from an LMM where emotional arousal is the dependent variable and the emotional expressions are the independent variables and the treatments are included as interaction effects. Only the non-Duchenne smiles are differently related to emotional arousal in the inquiry and advocacy treatments. This treatment interaction effect is positive in the inquiry treatment and negative in the advocacy treatment. In other words, arousal increases in the bin count of non-Duchenne smiles in the inquiry treatment, but in the advocacy treatment arousal decreases in the bin count of non-Duchenne smiles. There are no significant relationships between emotional arousal and the Duchenne smile 
Table 1 How the emotional expressions are related to emotional arousal, LMM estimates

\begin{tabular}{lc}
\hline Independent variable & Estimate $(S E M) \times 1000$ \\
\hline Intercept) & $848.3(104.0)^{* * * *}$ \\
Duchenne & $44.8(29.9)$ \\
Non-Duchenne & $490.9(36.5)^{* * *}$ \\
Furrowed brows & $-15.8(13.7)$ \\
Duchenne $\times$ advocacy & $56.3(40.1)$ \\
Duchenne $\times$ inquiry & $-34.5(37.8)$ \\
Non-Duchenne $\times$ advocacy & $-986.5(61.7)^{* * *}$ \\
Non-Duchenne $\times$ inquiry & $-188.4(53.4)^{* * *}$ \\
Furrowed brows $\times$ advocacy & $14.1(20.7)$ \\
Furrowed brows $\times$ inquiry & $13.9(21.2)$ \\
Time & $-5.2(0.62)^{* * *}$ \\
\hline
\end{tabular}

The number of observations is 2106. The dependent variable is the ISCR score. The EMG bin counts are centered on subject means. The main treatment effects are omitted from the regression. The random effect standard deviations are: $\sigma_{0}=0.62, \sigma_{1}=0.52$. Asterisks represent significance levels: $* * * p<0.001$

nor between emotional arousal and the furrowed brows expression. These results confirm that the level of arousal is different in the inquiry and advocacy modes and the correlation between arousal and the non-Duchenne smile is different in the treatments.

The mean empathy score is $43.4(S D=23.7)$. Table 2 shows results from LMMs where each emotional expression and emotional arousal are in turn the dependent variables and the empathy score is the independent variable and the treatments are included as interaction effects. Empathy correlates with all the EMG bin counts as well as with the arousal score in the inquiry treatment, but in the advocacy treatment empathy correlates only with the non-Duchenne smile. With the Duchenne and non-Duchenne smiles this treatment effect is increasing, i.e. in the inquiry treatment subjects with a higher empathy score express a higher number of positive emotional expressions than subjects with a lower empathy score. With the furrowed brows expression, this treatment effect is decreasing, i.e. in the inquiry treatment subjects with a higher empathy score express a smaller number of negative emotional expressions than subjects with a lower empathy score. With arousal, the treatment effect is increasing but again only in the inquiry treatment.

\section{Discussion}

Our results show that positive emotional expressions are only observed in the inquiry mode. It is likely that people express both Duchenne and non-Duchenne smiles in interactions with other people. For this reason, we used a method that distinguished the Duchenne smiles from the non-Duchenne smiles, and this method of counting the smiles in 3-s bins ensures that the detection of these smiles is mutually exclusive. In other words, whenever a Duchenne smile is detected, our method rules out the 
Table 2 How empathy moderates the treatment effects of each emotional measure, LMM estimates

\begin{tabular}{lllll}
\hline $\begin{array}{l}\text { Independent } \\
\text { variable }\end{array}$ & Duchenne & Non-Duchenne & Furrowed brows & Arousal \\
\hline Intercept & $29.7(14.6)^{*}$ & $-4.10(12.6)$ & $214.1(33.0)^{* * *}$ & $85.7(10.6)^{* * *}$ \\
Empathy & $0.49(0.44)$ & $0.12(0.45)$ & $-0.86(1.2)$ & $0.14(0.33)$ \\
Advocacy & $-6.7(7.7)$ & $19.1(4.9)^{* * *}$ & $17.9(12.8)$ & $-13.1(5.5)^{*}$ \\
Inquiry & $51.1(7.7)^{* * *}$ & $18.2(4.9)^{* * *}$ & $-82.3(12.8)^{* * *}$ & $14.6(5.46)^{* *}$ \\
Empathy $\times$ & $-0.26(0.21)$ & $0.91(0.13)^{* * *}$ & $-0.02(0.34)$ & $0.058(0.15)$ \\
$\quad$ advocacy & $2.14(0.21)^{* * *}$ & $0.64(0.13)^{* * *}$ & $-2.2(0.34)^{* * *}$ & $0.94(0.15)^{* * *}$ \\
Empathy $\times$ inquiry & $-0.054(0.15)$ & $0.27(0.099)^{* *}$ & $0.028(0.25)$ & $-0.61(0.11)$ \\
Time & 1.0 & 0.64 & 1.65 & 0.65 \\
$\sigma_{0}$ & 0.56 & 0.60 & 1.58 & 0.39 \\
$\sigma_{1}$ & & & & \\
\hline
\end{tabular}

The number of observations is 2496 in models with EMG bin counts (reported in the duchenne, nonDuchenne, and furrowed brows columns) and 2106 in the model with ISCR (reported in the arousal column). Each psychophysiological score is in turn the dependent variable. Each cell shows the estimate $(S E M) \times$ 100. The empathy score is centered on its mean. Asterisks represent significance levels: $* p<0.05$, ${ }^{* *} p$ $<0.01, * * * p<0.001$

simultaneous expression of a non-Duchenne smile, and vice versa. The non-genuine smiles are more likely to be related to masked or feigned emotions than the genuine smiles. Previous literature has also found that the non-genuine smiles are expressed when experiencing negative emotions or in situations of deception (e.g. Ekman et al. 1988; Ekman 2003). In our experiment, the Duchenne smiles are only present in the inquiry mode whereas the non-Duchenne smiles are present in both inquiry and advocacy modes. These results on the specificity of facially expressed emotions are consistent with other experiments reporting the differential activation of genuine and non-genuine smiles on positively and negatively valenced stimuli (Ekman et al. 1990; Johnson et al. 2010; for opposing evidence see also Krumhuber and Manstead 2009). Related findings in the literature include the use of Duchenne smiles in persuasion (Gunnery and Hall 2014), as social reinforcers (Shore and Heerey 2011), and as honest signals of cooperation in a Prisoner's Dilemma game (Reed et al. 2012).

We were also interested to know how well the different emotional expressions in different treatments correlate with the internal emotional states. As we do not find a treatment effect for arousal, our initial assumption that arousal alone represents intrapersonal emotions within the treatments cannot be confirmed. However, we do find that the correlation between arousal and the non-Duchenne smiles is different in the inquiry and advocacy treatments. The levels of non-Duchenne smiles increase in the level of arousal in the inquiry treatment and decrease in the level of arousal in the advocacy treatment. ANS activity as measured by SCR is known to increase in facial expressivity (Adelmann and Zajonc 1989) and be specific to many discrete emotions (Kreibig 2010). Thus, one possible way to interpret this finding would be such that the non-Duchenne smile does not correspond to an actual intrapersonal emotion as its linear relationship to emotional arousal is different between the different treatments. This interpretation is in line with the monotonicity hypothesis (McIntosh 
1996; Soussignan 2002) that argues that autonomic arousal increases monotonously with the intensity of the facial expression. The monotonicity hypothesis would thus indicate that the non-Duchenne smile does not correlate with an internal emotional state. (It should be noted that the term 'intensity' in our experiment does not refer to the amplitude of the EMG signal but rather to intensity in the time domain, the count of 3-s bins within each 18-s stimuli where the expression was active.)

The empathy score is related to the emotional expressions and emotional arousal, a finding in line with research linking empathy to somatic responsivity (Nummenmaa et al. 2008; Sonnby-Borgström 2002). However, this effect is observed across all the emotional measures only in the inquiry treatment, and the main effect of empathy score is absent from all emotion measures. Although the advocacy treatment generates non-Duchenne smiles, furrowed brows and emotional arousal, only the non-Duchenne activity is related to the empathy score in that treatment. In other words, the higher the empathy score, the more there are non-Duchenne smiles, but not other expressions, across treatments. Taken together with the finding (reported in Table 1) that the ANS is not monotonously activated alongside the non-Duchenne smile this may implicate volitional initiation of non-genuine smiles when thinking about the statements in a way that reflects the subject's empathy.

Autonomic emotional arousal accompanies the emotional expressions in a way that is specific to the expressions. This finding is in line with facial feedback theories (Adelmann and Zajonc 1989) positing that afferent feedback from the facial muscles generates internal emotional states. Facial feedback is also relevant in explaining how emotions are transferred via facial mimicry (Hatfield et al. 1994) and how attribution of emotional states from emotional expressions explains mindreading processes (Goldman and Sripada 2005). It is hypothesized in the literature that empathy moderates, via the insula, the ability to read emotions from facial expressions by modulating emotional content (Carr et al. 2003; Hennenlotter et al. 2009). One future research direction would indeed be to study how emotion transfer relates to the experienced emotions in the inquiry and advocacy modes and the mediating role of empathy.

The passive treatment was always the last treatment that the subject went through, and the inquiry and advocacy treatments were presented in random order before the passive treatment. It is also possible that, as we compare changes in the psychophysiological variables between the main treatments and the passive treatment, our results are partly due to inactivity in the facial musculature or in the autonomous nervous system resulting from habituation to the stimuli. However, this is true in any psychophysiological study where activation levels are compared to baselines. Furthermore, it should be noted that no emotional cues were given to the subjects in any of the treatments, and that the subjects were neither instructed to pose the expressions nor experience the specific emotions. Therefore, we think it is unlikely that the passive treatment would have generated different activation levels if habituation effects were better controlled.

\section{Conclusions}

Our study brings to focus an important way through which interaction modes can influence group behavior: through one's intrapersonal emotional responses that are 
triggered by the modes one is adopting. The way a person interacts can change her own internal emotional state and her facial emotional expressions. Emotions are signaled by facial expressions and they affect the interaction in groups. As the main finding our study demonstrates that the inquiry mode can generate genuine positive emotional expressions that are not generated in the advocacy mode.

Our main conclusion for the negotiation context is that it is not enough to only pay attention to one's intended emotional signal in group interaction. One should also be aware of the possibility that the interaction mode one chooses can have an unintended effect on one's own emotional state and the signal generated by it. This insight offers new behavioral possibilities. The inquiry mode is known to lower defenses on the other (Schein 2013) but one can also intentionally use the mode to guarantee one's own positive facial expression. As we discussed in the Introduction, positivity is known to have a favorable impact on negotiations. Whether the positive emotional impact of the inquiry mode generates improved negotiation outcomes remains an interesting research direction in the future.

Over the past decade we have seen an enormous growth in the neuroeconomics literature (see e.g. Glimcher and Fehr 2013; Leppänen and Hämäläinen 2017) which studies individual decision making and social behavior. Recently also operational researchers have started to pay attention to behavioural effects in modeling as well as modelling behaviour (Hämäläinen et al. 2013; Franco and Hämäläinen 2016a, b). Research on group decisions making is increasingly interested in emotions (Olekalns and Druckman 2015; Martinovski 2015a). These developments are reflected in our second methodological conclusion: because emotions do play a key role in negotiations the use of psychophysiological measurements as well as brain imaging methods is likely to increase in group research and yield insights to the field. It is also important to recall that it is also possible to measure neural correlates of two-person social interactions (see e.g. Hari and Kujala 2009). We suggest that group decision researchers should increasingly use these new tools to help understand how people's emotional responses are related to group decisions. The resulting insights can then be used to find improved ways of supporting group decision processes.

Acknowledgements We would like to thank the editors and two anonymous reviewers for their valuable comments that have improved the quality of the paper.

Open Access This article is distributed under the terms of the Creative Commons Attribution 4.0 International License (http://creativecommons.org/licenses/by/4.0/), which permits unrestricted use, distribution, and reproduction in any medium, provided you give appropriate credit to the original author(s) and the source, provide a link to the Creative Commons license, and indicate if changes were made.

\section{References}

Adelmann PK, Zajonc RB (1989) Facial efference and the experience of emotion. Annu Rev Psychol 40:249-280. https://doi.org/10.1146/annurev.ps.40.020189.001341

Allred KG, Mallozzi JS, Matsui F, Raia CP (1997) The influence of anger and compassion on negotiation performance. Organ Behav Hum Decis Process 70:175-187. https://doi.org/10.1006/obhd.1997.2705

Argyris C, Schön D (1978) Organizational learning: a theory of action perspective. Addison Wesley, Reading Barsade S (2002) The ripple effect: emotional contagion and its influence on group behavior. Adm Sci Q 47:644-675. https://doi.org/10.2307/3094912 
Benedek M, Kaernbach C (2010) A continuous measure of phasic electrodermal activity. J Neurosci Methods 190:80-91. https://doi.org/10.1016/j.jneumeth.2010.04.028

Brett JM, Olekalns M, Friedman R, Goates N, Anderson C, Lisco CC (2007) Sticks and stones: language, face, and online dispute resolution. Acad Manag J 50:85-99

Broekens J, Jonker C, Meyer J (2010) Affective negotiation support systems. J Ambient Intell Smart Environ 2:121-144

Carr L, Iacoboni M, Dubeau M-C, Mazziotta JC, Lenzi GL (2003) Neural mechanisms of empathy in humans: a relay from neural systems for imitation to limbic areas. Proc Natl Acad Sci 100:5497-5502. https://doi.org/10.1073/pnas.0935845100

Chapman HA, Anderson AK (2013) Things rank and gross in nature: a review and synthesis of moral disgust. Psychol Bull 139:300-327

Christov-Moore L, Iacoboni M (2015) Emotions in interaction: toward a supraindividual study of empathy. In: Martinovski B (ed) Emotion in group decision and negotiation. Springer, Dordrecht, pp 1-32

Derks D, Fischer AH, Bos AE (2008) The role of emotion in computer-mediated communication: a review. Comput Hum Behav 24:766-785

Dimberg U, Lundquist L-O (1990) Gender differences in facial reactions to facial expressions. Biol Psychol 30:151-159. https://doi.org/10.1016/0301-0511(90)90024-Q

Druckman D, Olekalns M (2008) Emotions in negotiations. Group Decis Negot 17:1-11

Ekman P (2003) Darwin, deception, and facial expression. Ann N Y Acad Sci 1000:205-221

Ekman P, Friesen WV, O’Sullivan M (1988) Smiles when lying. J Pers Soc Psychol 54:414-420. https://d oi.org/10.1037/0022-3514.54.3.414

Ekman P, Davidson RJ, Friesen WV (1990) The Duchenne smile: emotional expression and brain physiology II. J Pers Soc Psychol 58:342-353

Forgas JP, George JM (2001) Affective influences on judgments and behavior in organizations: an information processing perspective. Organ Behav Hum Decis Process 86:3-34. https://doi.org/10.1006/ob hd.2001.2971

Franco LA, Hämäläinen RP (2016a) Engaging with behavioural OR: on methods, actors and praxis. In: Kunc M, Malpass J, White L (eds) Behavioural operational research: theory, methodology and practice. Palgrave, Macmillan, Basingstoke, pp 3-25

Franco LA, Hämäläinen RP (2016b) Behavioural operational research: returning to the roots of the OR profession. Eur J Oper Res 249:791-795

Frank MG, Ekman P (1993) Not all smiles are created equal: the differences between enjoyment and nonenjoyment smiles. Humor 6:9-26. https://doi.org/10.1515/humr.1993.6.1.9

Fredrickson BL (2001) The role of positive emotions in positive psychology: the broaden-and-build theory of positive emotions. Am Psychol 56:218-226. https://doi.org/10.1037/0003-066X.56.3.218

Fridlund AJ (1994) Human facial expression: an evolutionary view. Academic Press, London

Fridlund AJ, Cacioppo JT (1986) Guidelines for human electromyographic research. Psychophysiology 23:567-589. https://doi.org/10.1111/j.1469-8986.1986.tb00676.x

Friedman R, Anderson C, Brett J, Olekalns M, Goates N, Lisco CC (2004) The positive and negative effects of anger on dispute resolution: evidence from electronically mediated disputes. J Appl Psychol 89:369-376. https://doi.org/10.1037/0021-9010.89.2.369

Frijda NH (1994) Emotions are functional, most of the time. In: Ekman P, Davidson R (eds) The nature of emotion: fundamental questions. Oxford University Press, New York, pp 112-122

Glimcher PW, Fehr E (2013) Neuroeconomics: decision making and the brain. Elsevier, New York

Gneezy U, Imas A (2014) Materazzi effect and the strategic use of anger in competitive interactions. Proc Natl Acad Sci 111:1334-1337

Goldman AI, Sripada CS (2005) Simulationist models of face-based emotion recognition. Cognition 94:193-213. https://doi.org/10.1016/j.cognition.2004.01.005

Griessmair M (2017) Ups and downs: emotional dynamics in negotiations and their effects on (in) equity. Group Decis Negot 26:1061-1090

Griessmair M, Hippmann P, Gettinger J (2015) Emotions in e-negotiations. In: Martinovski B (ed) Emotion in group decision and negotiation. Springer, Dordrecht, pp 101-135

Gunnery SD, Hall JA (2014) The Duchenne smile and persuasion. J Nonverbal Behav 38:181-194. https:// doi.org/10.1007/s10919-014-0177-1

Hämäläinen RP, Saarinen E (2004) Systems intelligence: discovering a hidden competence in human action and organizational life. Helsinki University of Technology, Helsinki 
Hämäläinen RP, Luoma J, Saarinen E (2013) On the importance of behavioral operational research: the case of understanding and communicating about dynamic systems. Eur J Oper Res 228:623-634

Hari R, Kujala MV (2009) Brain basis of human social interaction: from concepts to brain imaging. Physiol Rev Publ 2:453-479

Hatfield E, Cacioppo JT, Rapson RL (1994) Emotional contagion. Cambridge University Press, Cambridge

Heckmann M, Teichmann B, Schröder U, Sprengelmeyer R, Ceballos-Baumann AO (2003) Pharmacologic denervation of frown muscles enhances baseline expression of happiness and decreases baseline expression of anger, sadness, and fear. J Am Acad Dermatol 49:213-216. https://doi.org/10.1067/S0 190-9622(03)00909-5

Heilman RM, Crişan LG, Houser D, Miclea M, Miu AC (2010) Emotion regulation and decision making under risk and uncertainty. Emotion 10:257

Hennenlotter A, Dresel C, Castrop F, Ceballos-Baumann AO, Wohlschläger AM, Haslinger B (2009) The link between facial feedback and neural activity within central circuitries of emotion-New insights from botulinum toxin-induced denervation of frown muscles. Cereb Cortex 19:537-542. https://doi. org/10.1093/cercor/bhn104

Hine MJ, Murphy SA, Weber M, Kersten G (2009) The role of emotion and language in dyadic enegotiations. Group Decis Negot 18:193-211. https://doi.org/10.1007/s10726-008-9151-9

Johnson KJ, Fredrickson BL (2005) "We all look the same to me": positive emotions eliminate the own-race bias in face recognition. Psychol Sci 16:875-881. https://doi.org/10.1111/j.1467-9280.2005.01631.x

Johnson KJ, Waugh CE, Fredrickson BL (2010) Smile to see the forest: facially expressed positive emotions broaden cognition. Cogn Emot 24:299-321. https://doi.org/10.1080/02699930903384667

Kappas A (2013) Social regulation of emotion: messy layers. Front Psychol 4:51

Kappas A, Bherer F, Thériault M (2000) Inhibiting facial expressions: limitations to the voluntary control of facial expressions of emotion. Motiv Emot 24:259-270. https://doi.org/10.1023/A:1010718815960

Kocher MG, Schudy S, Spantig L (2017) I lie? We lie! Why? experimental evidence of a dishonesty shift in groups. Manag Sci (articles in advance). https://doi.org/10.1287/mnsc.2017.2800

Kopelman S, Rosette AS, Thompson L (2006) The three faces of eve: strategic displays of positive, negative, and neutral emotions in negotiations. Organ Behav Hum Decis Process 99:81-101. https:// doi.org/10.1016/j.obhdp.2005.08.003

Kreibig SD (2010) Autonomic nervous system activity in emotion: a review. Biol Psychol 84:394-421. https://doi.org/10.1016/j.biopsycho.2010.03.010

Krumhuber EG, Manstead ASR (2009) Can Duchenne smiles be feigned? new evidence on felt and false smiles. Emotion 9:807-820. https://doi.org/10.1037/a0017844

Larsen JT, Norris CJ, Cacioppo JT (2003) Effects of positive and negative affect on electromyographic activity over zygomaticus major and corrugator supercilii. Psychophysiology 40:776-785. https://d oi.org/10.1111/1469-8986.00078

Larsen JT, Berntson GG, Poehlmann KM, Ito TA, Cacioppo JT (2008) The psychophysiology of emotion. In: Lewis M, Haviland-Jones JM, Barrett LF (eds) Handbook of emotions, 3rd edn. The Guilford Press, New York, pp 180-195

Leppänen I, Hämäläinen RP (2017) Emotions in a repeated Cournot duopoly game: a psychophysiological experiment. J Neurosci Psychol Econ 10:9-23. https://doi.org/10.1037/npe0000069

Luoma J, Hämäläinen RP, Saarinen E (2008) Perspectives on team dynamics: meta learning and systems intelligence. Syst Res Behav Sci 25:757-767

Luoma J, Hämäläinen RP, Saarinen E (2011) Acting with systems intelligence: integrating complex responsive processes with the systems perspective. J Oper Res Soc 62:3-11

Martinovski B (2015a) Emotion in group decision and negotiation. Springer, Dordrecht

Martinovski B (2015b) Discourse analysis of emotion in face-to-face group decision and negotiation. In: Martinovski B (ed) Emotion in group decision and negotiation. Springer, Dordrecht, pp 137-188

McIntosh DN (1996) Facial feedback hypotheses: evidence, implications, and directions. Motiv Emot 20:121-147

Mehrabian A, Epstein N (1972) A measure of emotional empathy. J Pers 40:525-543. https://doi.org/10. 1111/j.1467-6494.1972.tb00078.x

Morris MW, Keltner D (2000) How emotions work: the social functions of emotional expression in negotiations. In: Staw BM, Sutton RI (eds) Research in organizational behavior, vol 11. JAI, Amsterdam, pp $1-50$ 
Nummenmaa L, Hirvonen J, Parkkola R, Hietanen JK (2008) Is emotional contagion special? an fMRI study on neural systems of affective cognitive empathy. NeuroImage 43:571-580. https://doi.org/10. 1016/j.neuroimage.2008.08.014

Olekalns M, Druckman D (2015) With feeling: how emotions shape negotiation. In: Martinovski B (ed) Emotion in group decision and negotiation. Springer, Dordrecht, pp 33-50

Olekalns M, Smith PL (2007) Loose with the truth: predicting deception in negotiation. J Bus Ethics 76:225-238

Reed LI, Zeglen KN, Schmidt KL (2012) Facial expressions as honest signals of cooperative intent in a one-shot anonymous Prisoner's Dilemma game. Evol Hum Behav 33:200-209. https://doi.org/10.10 16/j.evolhumbehav.2011.09.003

Sanchez-Burks J, Huy QN (2009) Emotional aperture and strategic change: the accurate recognition of collective emotions. Organ Sci 20:22-34

Schein EH (2013) Humble inquiry: the gentle art of asking instead of telling. Berrett-Koehler Publishers, Oakland

Schweiger DM, Sandberg WR, Ragan JW (1986) Group approaches for improving strategic decision making: a comparative analysis of dialectical inquiry, devil's advocacy, and consensus. Acad Manag J 29:51-71. https://doi.org/10.5465/255859

Schweitzer ME, Gibson DE (2008) Fairness, feelings, and ethical decision-making: consequences of violating community standards of fairness. J Bus Ethics 77:287-301

Schwenk CR (1990) Effects of devil's advocacy and dialectical inquiry on decision making: a meta-analysis. Organ Behav Hum Decis Process 47:161-176. https://doi.org/10.1016/0749-5978(90)90051-A

Sell A, Tooby J, Cosmides L (2009) Formidability and the logic of human anger. Proc Natl Acad Sci 106:15073-15078

Shore DM, Heerey EA (2011) The value of genuine and polite smiles. Emotion 11:169-174. https://doi. org/10.1037/a0022601

Sinaceur M, Tiedens LZ (2006) Get mad and get more than even: when and why anger expression is effective in negotiations. J Exp Soc Psychol 42:314-322. https://doi.org/10.1016/j.jesp.2005.05.002

Slotte S, Hämäläinen RP (2015) Decision structuring dialogue. EURO J Decis Process 1:141-159

Sonnby-Borgström M (2002) Automatic mimicry reactions as related to differences in emotional empathy. Scand J Psychol 43:433-443. https://doi.org/10.1111/1467-9450.00312

Soussignan R (2002) Duchenne smile, emotional experience, and autonomic reactivity: a test of the facial feedback hypothesis. Emotion 2:52-74. https://doi.org/10.1037/1528-3542.2.1.52

Steffen AC, Rockstroh B, Jansma B (2009) Brain evoked potentials reflect how emotional faces influence our decision making. J Neurosci Psychol Econ 2:32-40. https://doi.org/10.1037/a0015464

Sutter M (2009) Deception through telling the truth?! experimental evidence from individuals and teams. Econ J 119:47-60

Tamir M, Ford BQ (2012) When feeling bad is expected to be good: emotion regulation and outcome expectancies in social conflicts. Emotion 12:807

Thompson LL, Nadler J, Kim PH (1999) Some like it hot: the case for the emotional negotiator. In: Thompson LL, Levine JM, Messick DM (eds) Shared cognition in organizations: the management of knowledge. Erlbaum, Mahwah, pp 139-161

Törmänen J, Hämäläinen RP, Saarinen E (2016) Systems intelligence inventory. Learn Organ 23:218-231

Van Kleef GA, De Dreu CKW, Manstead ASR (2004) The interpersonal effects of anger and happiness in negotiations. J Pers Soc Psychol 86:57-76. https://doi.org/10.1037/0022-3514.86.1.57

van Kleef GA, Heerdink MW, Homan AC (2017) Emotional influence in groups: the dynamic nexus of affect, cognition, and behavior. Curr Opin Psychol 17:156-161

Von Scheve C, Ismer S (2013) Towards a theory of collective emotions. Emot Rev 5:406-413 